\title{
The Effect Of Group-Orientation Culture On Inter-Organizational Cooperation Mechanisms
}

Sungmin Ryu, Sungkyunkwan University, South Korea Chul Woo Moon, Sungkyunkwan University, South Korea

\begin{abstract}
Cooperation between exchange parties becomes a center for inter-organizational relationship. Cooperation reduces the attractiveness of opportunistic behavior that seeks short-term benefits, so it has been identified as a key factor for inter-organizational cooperation. Although several factors affecting cooperative relationship have been studied, the majority of inter-organizational studies are conducted on the basis of an individualistic perspective view of Western culture. This study introduces group-orientation culture and tries to enhance the understanding the effect of group-orientation culture on inter-organizational cooperation in the relationship between exchange parties. This study suggests that group-orientation culture influences the generation of informal cooperation between exchange parties. When a party expects harmonious relationship with its partner, the party develops the relational norm through accepting short-term disadvantages that are expected to be balanced out by longer-term advantages. However, exchange parties with a low group-orientation culture do not rely on formal cooperation mechanisms.
\end{abstract}

Keywords: Cooperative Strategy; Inter-Organizational Relationships; Group-Oriented Culture

\section{INTRODUCTION}

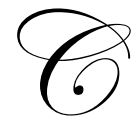

ooperation between exchange parties becomes a center for inter-organizational relationship (e.g., Gundlach, Achrol, \& Mentzer, 1995; Morgan \& Hunt, 1994; and Ganesan, 1994). Cooperation reduces the attractiveness of opportunistic behavior that seeks short-term benefits, so it has been identified as a key factor for inter-organizational cooperation (Morgan and Hunt, 1994). A high degree of cooperation is therefore a crucial factor for successful inter-organizational relationships (Gundlach, Achrol, and Mentzer, 1995). Thus, identifying the causal factor for cooperation could help exchange parties develop mutually beneficial long-term relationships with their partners.

Although several factors affecting cooperative relationship have been studied, the majority of interorganizational studies are conducted on the basis of an individualistic perspective view of Western culture (Lusch \& Brown, 1996; and Kumar, Scheer, \& Steenkamp, 1995). Thus, few studies have been conducted regarding the quality of inter-organizational relationships from the group-oriented perspective associated with Eastern cultures. For instance, the influence of culture (i.e., group-orientation culture) on inter-organizational relationship quality has been rarely addressed in the relevant literature (Robicheaux \& Coleman, 1994). Thus, it is necessary to explore the manner in which exchange parties in Eastern culture have been able to improve the quality of their relationships with their exchange partners.

Among the cultural dimensions developed by researchers, group-orientation culture has been a key cultural dimension that explains social interaction (e.g., Hofstede, 1991, 1980; and Trandis, 1995, and his colleagues, 1990, 1988). Group-orientation culture is defined as a culture in which a society consists of members who see themselves as a part of a group (Triandis, 1995). Hofstede (1991) reported that East-Asian countries, such as Korea, Japan, 
China, and Taiwan, show high levels of group-orientation culture. Group-orientation culture generates cohesiveness among the group members (Chen, Chen, \& Meindl, 1998) and develops a harmonious relationship (Fijneman, Willemsen, \& Poortinga, 1996; and Triandis, McCusker, \& Hui, 1990), whereas individualistic culture pays less attention to the relationship and is more task-oriented (Kim, et al, 1994). Thus, group-orientation culture develops a favorable condition for nurturing inter-organizational cooperation by forcing exchange parties to seek a cooperative relationship and actively solve inter-organizational problems to maintain a harmonious relationship with their partners.

The purpose of this study is to enhance the understanding the effect of group-orientation culture on interorganizational cooperation in the relationship between exchange parties. The group-orientation culture has been replicated at the inter-organizational group level and has been accepted as important for describing the difference among companies (Wuyts and Geyskens, 2005). Specifically, this study will introduce two types of cooperation formal cooperation and informal cooperation - and investigate how group-orientation culture affects cooperation.

The context of the study is the relationship between a manufacturer and its supplier. In the next section, we will provide theoretical backgrounds. We will also provide the dimensions of cooperation that is relevant to channel relationships. Finally, hypotheses will be proposed.

\section{THEORETICAL BACKGROUNDS \& HYPOTHESES}

\section{Group-orientation Culture}

To identify the most relevant characteristics of group-orientation culture in the context of interorganizational relationships, this study adopts the tacit assumptions of group-orientation culture instead of borrowing group-orientation culture directly from cross-cultural studies (e.g., Kim, 2003; and Putnam, 1994). In the supply chain context, the level of group-orientation culture is determined by how much priority one exchange party puts on its own benefits versus its partners' benefits (Kim, 2003). For instance, supply chain members in individualist cultures tend to emphasize self-interest and the maximization of individual benefits over exchange partner's gains (Lawler and Bacharach, 1987).

Group-orientation culture emphasizes members' association with a group (Hofstede, 1991). It lays emphasis on the obligation toward the group's well-being at the expense of individual desires. When there is a conflict between individual interests and the group's interest, collectivists give priority to the group's interest, whereas individualists give priority to self-interests (Triandis, 1995). Therefore, group-orientation culture in interorganizational relationship connotes an exchange party's concern for its exchange partner; it promotes unselfishness and places the interest of the group above self-interest (Wagner, 1995; and Kim et al, 1994).

Group-oriented members tend to identify themselves through their group membership, whereas individualists define themselves as an autonomous entity independent of a group (Wagner, 1995). Since a group strongly influences a group-oriented member's identity, group members perceive that they share 'common fate' among themselves (Triandis, McCusker, and Hui, 1990). Thus, in the inter-organizational relationship context, a shared fate provides a basis for a very close and intimate relationship between exchange parties. Since exchange parties need each other to perform their functions (i.e., a manufacturer needs suppliers of component parts to assemble the product), the common fate in group-orientation culture provides them with a solid basis for developing a long-term relationship with their partners.

Group-oriented members are sensitive to the ingroup-outgroup boundary (Triandis, 1995). In-group refers to a group of individuals with whom the person is willing to cooperate whilst out-group refers to a group of people with whom a person has no shared interest (Triandis, 1995). In a country with high group-orientation culture, once a party starts doing business with its new partner it implies that the party accepts the new partner within its in-group (Griffith, Hu, and Ryans, 2000). Thus, unless a party is prepared to treat its exchange partner as an in-group member, the party would not start doing business with that partner. 
The behaviour of collectivists toward in-group members is different from that exhibited toward out-group members (Triandis, McCusker, and Hui, 1990). Group-oriented members tend to recognize an in-group partner's trustworthiness and maintain cooperative relationships with other in-group partners (Brewer and Kramer, 1985), whereas they are likely to have a more superficial relationship with out-group (Kim et al, 1994). Earley (1993) reported that the performance of group-oriented members was relatively higher when working with in-group partners than with out-group members. Individualists, on the other hand, demonstrated higher performance when working alone rather than within an in-group or out-group.

Collectivists apply sanctions against members of an in-group who fail to deliver on their promises to exchange partners. Companies in Japan collectively sanction members who fail to deliver the expected level of performance. Once the underperforming supplier earns a bad reputation, other members punish the supplier by ceasing to transact business with that supplier. Thus, business parties in Japan are pressured to keep promises to partners and meet conventional rules.

\section{Cultural Variance within a Culture}

The behavior of each member differs, depending on the level of learning or interpretation of the culture particular to that person (Keesing, 1974), since culture is learned and interpreted by its members. Therefore, depending on a person's level of acculturation, various degrees of cultural tendencies may be observed (Wagner, 1995; and Triandis et al, 1985). As the person accepts and reflects the culture around him/her, so also will exchange parties tend to exhibit their culture as they interact in the inter-organizational relationship setting. Since a person learns culture as an individual, the focus on culture must be at the individual (unit) level rather than at the national level (Goodenough, 1971).

Though the influence of culture per person might be different, there is an overall influence of culture on each person (Kim et al, 1994). The personal difference regarding cultural acceptance does not mean that culture is totally reduced to an individual unit level. For instance, in countries with high group-orientation culture, children learn to suppress their self-centered tendencies and they receive compliments when they behave according to what their group expects (Triandis, 1995). Thus, people under the same culture show similar tendencies among themselves than people from different cultures (i.e., on average, group-oriented members show more group-oriented tendencies than individualists, whereas individualists reveal a self-centered tendency than collectivists). In sum, people show various levels of the dominant culture as individual units due to the difference in adopting the culture, but tend to possess the dominant culture than people in other cultures do as a group.

This study takes Keesing's (1974) view on culture - the variance of adopting dominant culture among individual units. Thus, the diverse level of group-orientation among the exchange parties is adopted as a variable for investigating the influence of group-orientation culture on inter-organizational cooperation.

\section{Cooperation}

Cooperation is defined as the firms' ability to collaborate and work together in a joint fashion toward their respective goals (Frazier, 1983). Cooperation is achieved by two types of mechanism - the formal and informal.

Contractual obligations, or rules and regulations, would constitute a formal cooperation mechanism (Smith et al, 1995). Contracts refer to the promise between exchange parties to project exchange into the future (Macneil, 1980). Contract between channel members describes the cooperative behavior with regard to designated tasks or periods. Therefore, each member is constrained to behave cooperatively by some formalized understanding.

Informal cooperation involves relational norms that are based on mutual understanding between channel members (Smith et al, 1995). For example, the relationship will be subject to good faith modification by both parties if a particular practice proves detrimental to either in the light of changed circumstances (Heide \& John, 1992). If a vendor cannot meet the deadline for supplying equipment parts, for instance, because of a strike or a flood, the buyer is likely to accept the vendor's request for delayed delivery as long as the buyer can sustain the shortage of equipment. Therefore, relational norms represent an important cooperation mechanism, especially when both 
exchange partners' relationships are long-term oriented (Axelrod, 1984).

Relational norms show two common characteristics. First, relational norms prescribe behavior and regulate proper and acceptable behavior of two exchange partners (Macneil, 1980). Second, relational norms vary with values relating to collective goals of the two exchange partners and with beliefs about appropriate means for attaining these goals (Cartwright and Schwartz, 1973). These characteristics of relational norms indicate that relational norms act as a cooperation mechanism between channel members.

Group-orientation culture influences exchange parties to bear long-term perspective in dealing with their partners. Group-orientation culture connotes an exchange party's concern for its exchange partner - it places the interest of the group above self-interest (Wagner, 1995). When organizations try to behave for both parties' wellbeing, the relationship between exchange parties is likely to be extended for a long time. Thus, they have a good chance of developing the relational norm through accepting short-term disadvantages that are expected to be balanced out by longer-term advantages (Noordewier John, and Nevin, 1990; and Lusch \& Brown, 1996). Therefore, firms with high group-orientation culture will gain cooperation through relational norms, a informal cooperation.

H1: There is a positive relationship between informal cooperation and group-orientation culture.

Since members with a low group-orientation culture do not care much about other members, they are less likely to have a long-term relationship. Thus, there is low level of long-term perspective among members with a low group-orientation culture. There is less degree of relational norms in a low level of long-term perspective because relational norms developed through accepting short-term disadvantage that is even out in the long run (Noordewier, John, \& Nevin, 1990). Instead, formal mechanism, such as a contract, is more prevalent in a low group-orientation culture because firms with low levels of group-orientation cannot depend on informal mechanisms to achieve cooperation. Therefore, firms with low level of group-orientation depend more on a contract.

Contracts contain the notion of legitimacy which forces exchange parties to observe the terms of the contract (Macneil, 1980). Exchange parties with contracts are therefore constrained to behave in certain ways, as formalized by the written contract. Thus, hard contracts constitute a formal governance mechanism in the exchange relationship (Uzzi, 1999).

Contract means a promise between exchange parties to project exchange into the future (Macneil, 1980). Contracts therefore shape relationships in the future, so they would not exist unless some expectation of future dealings existed. Since exchange parties cannot predict the future perfectly, the content of contract may not reflect the future contingencies well. Either party may be vulnerable to the other if one tries to take advantage of unclear or missing contract terms. Thus, when an exchange party tries to take advantage of a formal contract, parties with group-orientation culture face difficulty in dealing with this opportunistic partner since confrontation with other members is highly undesirable in a group-orientation culture (Triandis et al, 1988). Exchange parties with a high level of group-orientation culture therefore prefer not to rely on a contract - a formal cooperation mechanism.

H2: There is a negative relationship between formal cooperation and group-orientation culture.

\section{RESEARCH DESIGN}

\section{Context}

To test the hypotheses, we examined the purchasing relationship between manufacturers and their suppliers in Korea. We selected Korea for two key reasons. First, Korea is among the highest group-orientation cultures (Hofstede, 1991) and second, even though Korea has rapidly developed over the past 30 years, research about interorganizational relationships in Korea has been rarely done. Therefore, it is worthwhile to extend our knowledge of inter-organizational relationships in Korea. 


\section{Sample}

Included in the sample were 800 manufacturers that belong to SIC codes 3011 to 3999 . The sample of respondents was drawn from a variety of inter-organizational relationships to enhance the generalizability of the results through minimizing the effect of industry-specific characteristics.

Each informant was subsequently mailed a questionnaire and requested to complete it with respect to a major supplier. After callbacks and a second mailing, 192 were collected. The response rate is approximately $24 \%$. Non-response bias was evaluated by comparing early with late respondents. No significant differences were found on the variables "number of employees", "percentage of purchasing volume" and "years of experience", which suggests that non-response bias may not exist.

\section{Measurement}

\section{Group-orientation Culture}

Six items were used to measure the group-orientation culture: 1) the prevalence of an'us' consciousness, 2) the group as a base of identity, 3) emotional dependence on the organization that offers protection in exchange for loyalty, 4) taking care of oneself only, 5) tendency of solving problems through groups rather than through individual means, and 6) concern about how one's country is perceived by other nations. The first four items were used by Hofstede (1980) and the fifth and sixth items were adopted by Early (1993) and Triandis, McCusker, and Hui (1990) each.

\section{Cooperation}

Cooperation type was measured so that formal cooperation and informal cooperation could be distinguished. Formal cooperation was characterized by explicit, precise descriptions of each party's role, responsibilities, legal remedies for performance failures, and the method of conflict resolution. Informal cooperation was characterized more by the reliance on mutual understanding (as opposed to contract stipulations) of each party's role, responsibilities, remedies for performance failures and the way of resolution for conflict. These items were used by Lusch \& Brown (1996).

\section{ANALYSIS AND RESULTS}

Reliability of independent variables and correlations among them are shown in Tables 1 and 2, respectively. In all of the items, exchange parties in Korea show higher cooperation. This is in accordance with current literature that Asian countries have more long- term orientation (Hofstede, 1991).

\section{Tests of Hypotheses}

$\mathrm{H} 1$ argues that group-orientation culture affects the buyer's use of an informal cooperation mechanism. The results in Table 3 indicate that $\mathrm{H} 1$ is supported $(\beta=.2207, \mathrm{p} \leq .05)$.

In contrast, $\mathrm{H} 2$ argues that buyers with group-orientation culture are less likely to rely on formal cooperation. We thought that existence of an informal cooperation mechanism in the group-orientation culture negatively affects the relationship between group-orientation culture and formal cooperation. However, buyers with a group-orientation culture have nothing to do with formal cooperation. The results in Table 3 show that $\mathrm{H} 2$ is not supported.

A control variable of buyer's power over supplier did not affect the buyer's informal and formal cooperation mechanisms at the p-level of .05. 
Table 1: Reliability for Independent Variables

\begin{tabular}{lc}
\hline Group-orientation Culture & CR $=.71$ \\
\hline In our society, & .71 \\
1. It matters to people how our country is perceived by other nations. & $*$ \\
2. "Us" consciousness holds sway. & $*$ \\
3. Each individual is supposed to take care of himself/herself only. & .55 \\
4. People tend to solve problems through group rather than individual effort & $*$ \\
5. A person's identity is based on the group. & .70 \\
6. People are emotionally dependent on the organization in terms of protection offered in exchange for loyalty. & .55 \\
\hline Formal Cooperation $\quad$ CR: .82 & .77 \\
1: mutual understanding of the roles and responsibility & .53 \\
2: mutual understanding of the behavior in case of unplanned event & .70 \\
3: mutual understanding of how disagreements will be resolved & .79 \\
\hline Informal Cooperation & .68 \\
1: precise definition of roles and responsibility in contract & \\
2: detailed direction in contract about behavior for unplanned event & \\
3: precise contract statement of how disagreements will be resolved & \\
\hline$\chi^{2}(32)=41.48$ (p=.13), GFI $=.93$ AGFI $=0.87$, CFI $=.95$, RMSEA $=.054$, & \\
\hline
\end{tabular}

Table 2: Correlation Matrix

\begin{tabular}{lccc}
\hline & Group & Informal & Formal \\
\hline Group & 1.0000 & & \\
Informal & .2011 & 1.0000 & \\
Formal & -.2562 & .1925 & 1.0000 \\
\hline
\end{tabular}

Table 3: Regression Analysis for Hypothesis

\begin{tabular}{lcc}
\hline & \multicolumn{2}{c}{ Dependent Variables } \\
\hline Independent Variables & Informal & Formal \\
\hline Group & .2207 & .0125 \\
& $(2.152)^{\mathrm{a}}$ & $(.136)$ \\
Power & -.0121 & .0905 \\
& $(-.105)$ & $(.702)$ \\
R Square & .0720 & .0420 \\
\hline
\end{tabular}

$\mathrm{a}:$ reject Ho at $\mathrm{p}<.05$ (1-tailed test.)

${ }^{\mathrm{b}}$ : reject Ho at $\mathrm{p}<.01$ (1-tailed test.)

Power: control variable

\section{DISCUSSION}

\section{Theoretical Implication}

These results indicate that the relationship between exchange parties is significantly affected by the grouporientation culture. Especially, group-orientation culture positively influences the use of informal cooperation. This result implies that it is the group-orientation culture that generates informal cooperation between exchange parties.

Companies with a group-orientation culture expect benefits from a harmonious relationship with their exchange parties. When a party expects harmonious relationship with its partner, the party develops the relational norm through accepting short-term disadvantages that are expected to be balanced out by longer-term advantages (Lusch \& Brown, 1996). Thus, they do not risk self interest seeking behavior of their partners. If a party acts for its own interest only, they would have to give up benefits from the relationship with its partners. Thus, companies with a high group-orientation generate informal cooperation. 
In contrast, companies with a group-orientation culture do not show any tendency regarding the use of formal cooperation. Since exchange parties with a group-orientation culture consider mutual benefit from the relationship with their partners, they are least expected to use a formal cooperation mechanism, such as contract. However, exchange parties with a group-orientation culture are not associated with the use of formal cooperation.

\section{Managerial Implications}

Since many exchange parties operate globally, understanding national culture is important. When a party decides to establish a branch in a foreign country, it should adapt management practices to fit the prevailing national culture and develop relationship strategies that fit within the host culture.

According to these research findings, group-oriented members appear to rely on informal cooperation in relation to their partners. Thus, a group-oriented company bases its interaction with exchange partners on harmonious and mutually beneficial relational norms. Thus, companies operating in a group-orientation culture should manage their relationships on a long-term basis.

\section{LIMITATIONS}

We examined only one dimension of culture; that is, group-orientation. In particular, the study does not include other cultural dimensions, such as a long-term orientation or power distance (Hofstede, 1991). These other cultural dimensions could affect the relationship between exchange parties. Therefore, the results obtained from cooperation are limited.

Another limitation of the study is the small sample of companies. Though the sample size is usually accepted in organization literature, the small sample size affects the stability of the parameter estimates. Therefore, the results obtained from the data should be interpreted with caution.

\section{AUTHOR INFORMATION}

Sungmin Ryu (Main Author) is Associate Professor of Marketing at Sungkyunkwan University. He is specialized in the areas of channels of distribution and business-to-business marketing. He has publications of Industrial Marketing Management, Journal of Business Research, Journal of Business-to-Business Marketing, Organization Science, and others. E-mail: smryu@ @sku.edu

Chul Woo Moon (Corresponding Author) is currently an associate professor of strategy at Sungkyunkwan University, Seoul, Korea. A Ph.D from the University of Maryland, College Park, Professor Moon held previous positions at Cleveland State University and Ewha Womans University. His current research interests include corporate diversification strategy and information sharing, theories on content-based competitive advantage, and arts-based creative management models. E-mail: cwmoon@skku.edu.

\section{REFERENCES}

1. Axelrod, R (1984), The Evolution of Cooperation. New York: Basic Books.

2. Bacharach, Samuel B. and Edward J. Lawler (1981), Bargaining: Power, Tactics, and outcomes. San Francisco: Jossey-Bass.

3. Cartwright, Bliss C., and Schwartz, Richard D.(1973). "The invocation of legal norms: an empirical investigation of Durkheim and Weber." American Sociological Review, 38: 340-354.

4. Chang, Juochung and Cherng G. Ding (1995), "The Influence of Culture on Industrial Buying Selection Criteria in Taiwon and Mainland China," Industrial Marketing Management, 24 277-84.

5. Chen, Chao C., Xiao-Ping Chen, and James R. Meindl (1998), "How Can Cooperation be Fostered? The Cultural Effects of Individualism-Collectivism," Academy of Management Review, 23(3), 285-304.

6. $\quad$ Earley, Christopher (1993), "East Meets West Meets Mideast: Further Explorations of Collectivistic and Individualistic Work Groups," Academy of Management Journal, 36 (2), 319-348. 
7. Fijneman, Yvonne, Madde Willemsen, and Ype Poortinga (1996), “Individualism - Collectivism,” Journal of Cross-Cultural Psychology 27 (4), 381-402

8. Foa, Uriel and Enna Foa (1974), Societal Structures of the Mind, Springfield, IL: Charles C. Thomas.

9. Frazier, Gary L (1983) "Interorganizational Exchange Behavior in Marketing Channels: A Broadened Perspective," Journal of Marketing, 47 (Fall 1983), 68-78.

10. Ganesan, Shankar (1994) "Determinants of Long-Term Orientation in Buyer-Seller Relationships," Journal of Marketing, 58(April), 1-19.

11. Goodenough, W.H (1971), Culture and Language, and Society. McCaleb Module in Anthropology. Reading, Mass: Addison-Wesley.

12. Griffith, David A, Michael Y Hu, and John K Ryans Jr (2000), "Process Standardization across Intra- and Inter- Cultural Relationships,” Journal of International Business Studies, 31 (2) 303-25

13. Gundlach, Gregory, Ravi Achrol, and John Mentzer (1995), "The Structure of Long-term orientation," Journal of Marketing, 59 (January), 78-92.

14. Heide, Jan B. and George John (1992), “Do Norms Matter in Marketing Relationships?” Journal of Marketing, 56(April), 32-44.

15. Hill, Charles W. (1990) "Cooperation, Opportunism, and the Invisible Hand: Implications for Transaction Cost Theory" Academy of Management Review, 15(3) 500-513.

16. Hofstede, Geert (1991), Cultures and Organization: Software of the mind. London: McGraw-Hill

17. Keesing, Roger (1974), "Theories of Culture," Annual Review of Anthropology, 3, 73-97.

18. Kim, Uichol, Harry Triandis, Cigdem Kagitcibasi, Sang Choi, and Gene. Yoon (1994), Individualism and Collectivism: Theory, Method and Applications. Newbury Park, California, Sage.

19. Kim Stephen and Ping-hung Hsieh (2003), "Interdependence and Its Consequences in Distributor-Supplier Relationships: a Distributor Perspective Through Response Surface Approach," Journal of Marketing Research, 40 (February), 101-112.

20. Kumar, Nirmalya, Lisa K. Scheer, and Jan-Benedict E. M. Steenkamp (1995), "The Effect of Perceived Interdependence on Dealer Attitudes," Journal of Marketing Research, 32 (August), 348- 356.

21. Lawler, Edward J. and Samuel B. Bacharach (1987), "Comparison of Dependence and Punitive Forms of Power," Social forces, 66 (2), 446-62.

22. Lusch, Robert F. and James R. Brown (1996), "Interdependency, Contracting, and Relational Behavior in Marketing Channels," Journal of Marketing, 60(October), 19-38.

23. Mackneil, Ian R. (1980), The New social Contract, New Haven, CT: Yale University.

24. Morgan, Robert M and Shelby D. Hunt (1994), "The Commitment-Trust Theory of Relationship Marketing," Journal of Marketing, 58 (July), 20-38.

25. Noordewier, Thomas G., George john, and John R. Nevin (1990), "Performance Outcomes of Purchasing Arrangements in Industrial Buyer-Vendor Relationships," Journal of Marketing, 54(October) 108-122.

26. Robicheaux, Robert A. \& James E. Coleman (1994), "The Structure of Marketing Channel Relationships," Journal of the Academy of Marketing Science, 22(1), 38-51.

27. Smith, Ken, G., Stephen J. Carroll, and Susan J. Ashford (1995), "Intra- and Interorganizational Cooperation: Toward a Research Agenda," Academy of Management Journal 38 (1) 7-23.

28. Triandis, Harry C. (1995), Individualism and Collectivism, Boulder Co; Westview press.

29. Triandis, Harry C., McCusker, C., and C.H. Hui (1990), "Multimethod probes of individualism and collectivism. Journal of Personality and Social Psychology 59, 1006-1020.

30. Triandis, Harry C., Robert Bontempo, Marcelo J. Villareal, Masaaki Asai, and Nydia Lucca (1988), "Individualism and Collectivism: Cross-Cultural Perspectives on Self-In-group Relationships," Journal of Personality and Social Psychology, 54 (2) 323-338.

31. Wagner III, John A. (1995), "Studies of individualism-Collectivism: Effects on Cooperation in Groups," Academy of Management Journal, 38(1), 152-172.

32. Wuyts, Stefan, and Inge Geyskens (2005), "The Formation of Buyer-Supplier Relationships: Detailed Contracts Drafting and Close Partner Selection,” Journal of Marketing, 69 (October), 103-117. 